\title{
ARTICLE
}

\section{Does Teacher Training Narrow the Educational Gap between Urban and Rural Students? Empirical Evidence from CEPS Baseline Data}

\author{
Ran Sun, Ping Du \\ Faculty of Education, Beijing Normal University, Beijing 100875, China
}

\begin{abstract}
Based on the baseline data of the China Education Panel Survey, this paper explored the relationship between teacher training and academic performance in urban and rural samples respectively and the impact of teacher training on the urban-rural gap of students' academic performance. The results showed that: firstly, there was a significant urban-rural gap in academic performance, and the gap in high quantiles and language subjects were even larger. Secondly, the results of unconditional quantile regression showed that teacher training could improve the performance of urban students with different academic levels and rural students with intermediate or above academic levels, but it cannot improve the performance of rural students with lower academic levels. In addition, the overall effect of teacher training in urban areas is significantly higher than that in rural areas. Thirdly, different quantiles of Oaxaca-Blinder decomposition found that the endowment effect and the coefficient effect of teacher training were the important causes of the urban-rural performance gap, but the relative sizes of the two were different according to the different grades and different quantiles of performance distribution. Therefore, to increase the training opportunities and improve the training quality of rural teachers as well as enhance the resource conversion rate of rural students are of great practical significance for narrowing the urbanrural performance gap.
\end{abstract}

Best Evidence in Chinese Education 2021; 9(2):1243-1261.

Doi: 10.15354/bece.21.ar036.

How to Cite: Sun, R., \& Du, P. (2021). Does teacher training narrow the educational gap between urban and rural students? Empirical evidence from CEPS baseline data. Best Evidence in Chinese Education, 9(2):1243-1261. 
Sun \& Du. Teacher Training in Educational Gap between Urban and Rural Students.

Keywords: Teacher Training, Urban-Rural Gap, Unconditional Quantile Regression, Oaxaca-Blinder Decomposition

About the Author: Ran Sun, Faculty of Education, Beijing Normal University, Beijing 100875, China. E-mail: ransunsunny@163.com

Correspondence to: Ping Du, Faculty of Education, Beijing Normal University, Beijing 100875, China. E-mail: duping868@sina.com

Conflict of Interests: None.

(C) 2021 Insights Publisher. All rights reserved.

(c) (i) (\$) Creative Commons Non Commercial CC BY-NC: This article is distributed under the terms of the Creative Commons Attribution-NonCommercial 4.0 License (http://www.creativecommons.org/licenses/by-nc/4.0/) which permits non-commercial use, reproduction and distribution of the work without further permission provided the original work is attributed by the Insights Publisher. 


\section{Introduction}

7 HE development of China's compulsory education has achieved remarkable results. However, the academic development of rural students still lags behind that of urban students (Zhu, Li \& Song, 2017; Peng, 2014; Qi \& Zheng, 2019). Access to education is dependent on the path (Chen, 2008). The gap in the compulsory education stage will cause huge differences in the enrollment rate and academic development of urban and rural students in the subsequent learning stage (Zheng, Sun \& Lu, 2019; Zhang, 2019), and ultimately affect the overall level of social human capital accumulation (Wang et al., 2018). Therefore, it is crucial to reveal the reasons behind the gap in academic development of urban and rural students in the compulsory education stage. Studies have pointed out that the quality of rural teachers is much lower than that of urban teachers is the key reason for the gap between urban and rural students' academic development (Qi \& Zheng, 2019; Zong et al., 2018). Therefore, the Chinese government has invested a lot of resources in extensive teacher training programs to improve the overall quality of rural teachers. So, does rural teacher training really improve the quality of rural education and thereby narrow the gap with urban education development? In this paper, based on the CEPS baseline survey data, we used unconditional quantile regression and Oaxaca-Blinder decomposition technology to explore the above problems.

\section{Literature Review}

\section{The Relationship between Teacher Training and Stu- dent Academic Development}

Studies have found that on-the-job training can help teachers improve their teaching practice (Ross \& Bruce, 2007), and enhance their sense of self-efficacy (Liu, Ma \& Kang, 2020), thereby improving their professional development level and students' academic performance. For example, Angrist and Lavy (2001) pointed out that in 1995 several public schools in Jerusalem received an education and training fund dedicated to improving teachers' reading, math, and English teaching skills, while teachers in other schools were not subject to this project. Based on this, they used the technique of double difference to find that teacher training could improve the mathematics and reading performance of elementary school students. In addition, the authors believed that teacher training is more cost-effective for improving student performance than adjusting class size or teaching hours. Zhou and Yang (2019) used CEPS data to find that China's rural teacher training improves students' academic performance, and the abovementioned positive effects were more pronounced among boys and lower-grade students.

Nevertheless, some studies based on randomized controlled trials, quasiexperimental design, and training program evaluation have found that teacher training 
has no significant effect on student performance. For example, Jacob and Lefgren (2004) used the breakpoint regression method for the educational reform implemented by the Chicago Public School System in $1996^{\underline{1}}$ and found that teacher training had no obvious effect on improving the mathematics and reading performance of primary school students. Moreover, this result exists steadily among students of different abilities, genders, races, and family incomes. However, the authors believed that the target group of this educational reform was schools with high levels of poverty and extremely backward student academic development, and the lack of structure and poor quality of training activities may be the reasons for the ineffectiveness of training. Zhang, Lai and Pang (2013) conducted a randomized controlled trial of training intervention for English teachers in schools for children of migrant workers in Beijing. The results showed that short-term and high-intensity on-the-job training had no significant impact on the teaching level of English teachers and the English performance of students. By evaluating the effectiveness of large-scale rural teacher training programs in China, Loyalka et al. (2019) found that teachers' knowledge and teaching habits, students' academic performance, psychological factors in specific subjects, or dropout behavior are not affected by this training project.

Furthermore, most of the existing studies reveal the relationship between teacher training and student academic development in an average sense. The key assumption is that there is no difference in the effect of teacher training for students with better and poorer grades in the class (Lounkeaw, 2013). However, students with poor grades tend to learn passively, while students with excellent grades learn more actively (Qing, 2009). Then when participating in training squeezes the time allocation of teachers in teaching, preparing lessons, and tutoring students (Zhou \& Yang, 2019), the performance of students with poor grades may further decline and it is more difficult to benefit from teacher training, while students with good grades are more likely to benefit from teacher training. May be undisturbed and benefit from teacher training. Therefore, in the sense of super-average, it is still worth in-depth to reveal the relationship between teacher training and student academic development more accurately.

\section{The Training Status of Urban and Rural Teachers}

Since the 21st century, China's teacher training has made great progress (Pang et al., 2020). However, practical problems still exist in the training of rural teachers, such as lack of training funds and opportunities, formalized training process and low quality of training (Zhao \& Xie, 2019).

On the one hand, a large number of rural schools are experiencing inadequate implementation of teacher training funding guarantee policies, which to a certain extent limits the training opportunities for rural teachers. For example, a number of national and regional surveys have shown that many rural schools have not fully implemented the requirement that $5 \%$ of the public funds for elementary and middle school teachers should be used for teacher training (Wu \& Qin, 2020; Ministry of Education of China, 2019). On the other hand, the training activities received by rural teachers may be of poor quality, lack of appropriate training content, difficult to meet the characteristics of 
rural schools, and out of touch with their professional development needs (Pang et al., 2020; Chen \& Wang, 2013). Therefore, the training opportunities and quality of rural teachers may not be as good as urban teachers. If it can be proved that teacher training has a boosting effect on students' academic development, we have reason to speculate that the gap in training opportunities and training quality between urban and rural teachers may be an important reason for the gap in the academic development of Chinese urban and rural students.

Based on the above literature review, we proposed the following hypotheses to be verified:

Hypothesis 1: The academic development of rural students lags behind that of urban students significantly.

Hypothesis 2: Teacher training has a boosting effect on students' academic development, but this effect is heterogeneous among students with different academic foundations.

Hypothesis 3: The gap in teacher training between urban and rural areas is an important reason for the differences in student performance between urban and rural areas.

\section{Research Design}

\section{Data Sources}

The data comes from the China Education Panel Survey (CEPS) implemented by the China Survey and Data Center of Renmin University of China from 2013 to 2014. The CEPS was a large-scale follow-up survey project with national representativeness. Taking the two cohorts of the seventh and ninth grades as the starting point for the survey, 28 counties (districts), 112 schools, 438 classes, and 19,487 students were randomly selected across China as the survey subjects. It collected information on family and school resources, teacher training status, students' academic performance, and basic characteristics of students, families and schools, which meet our research needs. After deleting a small number of invalid samples and samples with missing values in key variables, the subsequent analysis of the student sample size is 10,628 , including 5,743 urban samples and 4,885 rural samples.

\section{Variable Selection}

\section{- Urban-Rural Variables}

Based on the information provided by the principal's questionnaire, we defined schools located in the central city, fringe urban areas, and urban-rural junctions of cities/counties as "urban schools", and schools located in towns and rural areas as "rural schools". In Table 1, there are 3,065, 2,487, 2,678, and 2,398 students in seventh grade urban students, seventh grade rural students, ninth grade urban students, and ninth grade rural students, respectively. 


\section{Table 1. Descriptive Statistics of Main Variables.}

\begin{tabular}{|c|c|c|c|c|c|c|c|}
\hline \multirow[b]{2}{*}{ Dimension } & \multirow[b]{2}{*}{ Variable Name } & \multicolumn{3}{|c|}{ Seventh Grade } & \multicolumn{3}{|c|}{ Ninth Grade } \\
\hline & & $\begin{array}{l}\text { City } \\
\text { Sample }\end{array}$ & $\begin{array}{l}\text { Rural } \\
\text { Sample } \\
\end{array}$ & $\begin{array}{l}\text { Mean } \\
\text { Difference }\end{array}$ & $\begin{array}{l}\text { City } \\
\text { Sample }\end{array}$ & $\begin{array}{l}\text { Rural } \\
\text { Sample }\end{array}$ & $\begin{array}{l}\text { Mean } \\
\text { Difference }\end{array}$ \\
\hline $\begin{array}{l}\text { Independent } \\
\text { variable }\end{array}$ & $\begin{array}{l}\text { Teacher training fre- } \\
\text { quency }\end{array}$ & 22.973 & 15.545 & $7.428^{* * *}$ & 20.501 & 15.844 & $4.658^{\star \star \star}$ \\
\hline \multirow[t]{3}{*}{$\begin{array}{l}\text { Dependent } \\
\text { variable }\end{array}$} & $\begin{array}{l}\text { Cognitive performance } \\
\text { weighted language } \\
\text { performance }\end{array}$ & 45.535 & 35.754 & $9.781^{* \star *}$ & 45.254 & 35.595 & $9.659^{* * *}$ \\
\hline & $\begin{array}{l}\text { Cognitive performance } \\
\text { weighted mathematics } \\
\text { performance }\end{array}$ & 39.418 & 31.922 & $7.496^{\star \star \star}$ & 39.245 & 31.624 & $7.620^{\star \star \star}$ \\
\hline & $\begin{array}{l}\text { Cognitive performance } \\
\text { weighted English per- } \\
\text { formance }\end{array}$ & 46.946 & 38.241 & $8.705^{\star \star *}$ & 46.644 & 38.617 & $8.027^{\star \star \star}$ \\
\hline \multirow{4}{*}{$\begin{array}{l}\text { Student level } \\
\text { Face variable }\end{array}$} & Student gender & 0.528 & 0.532 & 0.004 & 0.502 & 0.490 & 0.012 \\
\hline & Is it an only child & 0.524 & 0.263 & $0.261^{* \star *}$ & 0.549 & 0.271 & $0.278^{\star \star \star}$ \\
\hline & $\begin{array}{l}\text { Have you received } \\
\text { preschool education }\end{array}$ & 0.843 & 0.743 & $0.100^{\star \star *}$ & 0.816 & 0.727 & $0.089^{\star \star \star}$ \\
\hline & Cognitive performance & 44.021 & 39.069 & $4.952^{\star \star \star}$ & 45.719 & 37.743 & $7.976^{\star \star \star}$ \\
\hline \multirow[t]{4}{*}{$\begin{array}{l}\text { Family layer } \\
\text { Face variable }\end{array}$} & $\begin{array}{l}\text { Family financial situa- } \\
\text { tion-Poor }\end{array}$ & $16.25 \%$ & $28.31 \%$ & 1 & $15.23 \%$ & $25.38 \%$ & l \\
\hline & $\begin{array}{l}\text { Family financial status- } \\
\text { Average }\end{array}$ & $76.74 \%$ & $67.42 \%$ & l & $77.91 \%$ & $70.41 \%$ & 1 \\
\hline & $\begin{array}{l}\text { Family financial status- } \\
\text { Rich }\end{array}$ & $7.00 \%$ & $4.27 \%$ & l & $6.86 \%$ & $4.20 \%$ & l \\
\hline & $\begin{array}{l}\text { Maximum years of } \\
\text { education for parents }\end{array}$ & 11.563 & 9.689 & $1.874^{\star \star \star}$ & 11.414 & 9.344 & $2.070^{* \star *}$ \\
\hline \multirow[t]{5}{*}{$\begin{array}{l}\text { School level } \\
\text { Face variable }\end{array}$} & $\begin{array}{l}\text { School Ranking- } \\
\text { Medium and below }\end{array}$ & $15.08 \%$ & $29.25 \%$ & l & $13.00 \%$ & $28.78 \%$ & l \\
\hline & $\begin{array}{l}\text { School Ranking-Upper } \\
\text { Middle }\end{array}$ & $50.70 \%$ & $70.75 \%$ & l & $48.59 \%$ & $71.22 \%$ & l \\
\hline & School Ranking-Best & $34.22 \%$ & 0 & 1 & $38.41 \%$ & 0 & 1 \\
\hline & $\begin{array}{l}\text { Proportion of under- } \\
\text { graduate teachers }\end{array}$ & 0.808 & 0.668 & $0.139^{\star \star \star}$ & 0.813 & 0.648 & $0.165^{\star * *}$ \\
\hline & $\begin{array}{l}\text { Proportion of teachers } \\
\text { graduated from normal } \\
\text { majors or colleges }\end{array}$ & 0.897 & 0.875 & $0.022^{* \star *}$ & 0.897 & 0.857 & $0.040^{* \star *}$ \\
\hline Sample size & & 3,065 & 2,487 & 1 & 2,678 & 2,398 & 1 \\
\hline
\end{tabular}

\section{- Student Performance}

The dependent variables were the students' Chinese, math, and English scores. In order to increase the comparability of academic performance in different schools and regions, we used the regional and school-comparable student cognitive performance data collected by the CEPS project team. First, generate the school-level average cognitive performance index, then weight the students' performance in the school, and finally obtain the variables of the three science achievements. In Table 1, in the sample of students in the two grades, the average scores of rural students were significantly lower than those 
of urban students; in terms of subject, the gap was the largest in Chinese, followed by English, and the smallest in mathematics.

\section{- $\quad$ Teacher Training}

The core explanatory variable was teacher training. It came from the frequency information of various teacher training conducted by schools provided by the principal questionnaire, which was a continuous variable. Table 1 shows that the frequency of teacher training in rural areas was significantly lower than that in urban areas.

\section{- Control Variable}

This study contains three groups of control variables at the student level, family level and school level. Student-level variables included gender $(0=$ female, $1=$ male $)$, only child $(0=$ no, $1=$ yes $)$, preschool education $(0=$ no, $1=$ yes $)$, and student cognitive test scores. Family-level variables included family economic status $(1=$ poverty, $2=$ average, 3 = abundant) and the parent's highest level of education. School-level variables included school rankings ( 1 = medium and below, $2=$ upper-middle, $3=$ best $)$, the proportion of teachers with a bachelor's degree, and the proportion of teachers who graduated from teachers' colleges or majors. Table 1 shows that compared with urban students, the proportion of only-children, the proportion of preschool education and cognitive performance among rural students were significantly lower; parents' educational level was significantly lower; family economic conditions were generally worse; schools ranked lower; the proportion of teachers with a bachelor's degree and the proportion of teachers who graduated from teachers' majors or colleges were significantly lower.

\section{Research Methodology}

\section{Unconditional Quantile Regression}

To investigate the impact of teacher training on the performance of urban and rural students at different points of student performance distribution, we adopted Unconditional Quantile Regression (UQR) to conduct research. Following is an example of Chinese score. UQR mainly uses the re-centered influence function (RIF) of distribution statistics for data conversion (Firpo, Fortin \& Lemieux, 2009). For the unconditional quantile $\left(Q_{\tau}\right)$ of the dependent variable student's Chinese score, $F_{\text {Score }}\left(Q_{\tau}\right)=\tau_{0} f_{\text {Score }}\left(Q_{\tau}\right)$ is the marginal density function of the student's score distribution, and $\mathrm{I}(\bullet)$ is the indicator function. Its RIF can be recorded as:

$$
R I F\left(\text { Score }, Q_{\tau}\right)=Q_{\tau}+\frac{\tau-I\left(\text { Score } \leq Q_{\tau}\right)}{f_{\text {Score }}\left(Q_{\tau}\right)}
$$

The average value of RIF is equal to the corresponding target statistic, namely $\mathrm{E}[\mathrm{RIF}(\mathrm{Score}, \mathrm{Q} \tau) \mid \mathrm{X}]=\mathrm{Q} \tau($ Score $)$. Then the marginal effect of $\mathrm{UQR}$ is expressed as: 


$$
U Q P E(\tau)=\int \frac{\partial E\left(R I F\left(\text { Score }, Q_{\tau}\right) \mid X\right)}{\partial X} d F_{X}
$$

UQR can be regressed on any quantile. Due to space limitations, the follow-up analysis only presents the estimated results of the effect of teacher training on urban and rural student performance at the 30th, 50th, and 70th points of the student performance distribution.

\section{Oaxaca-Blinder Decomposition}

With the help of OB decomposition (Blinder, 1973; Oaxaca, 1973), we focused on the decomposition of the performance gap between urban and rural students in teacher training. We take the Chinese score as an example to detail the decomposition process. $\Delta$ is the urban-rural gap of students' language performance, and its $\mathrm{OB}$ decomposition form is as follows:

$$
\Delta=E(\text { Score } \mid \text { Urban })-E(\text { Score } \mid \text { Rural })=\left(\bar{X}_{u}-\bar{X}_{r}\right) \cdot \hat{\beta}_{r}+\left(\hat{\beta}_{u}-\hat{\beta}_{r}\right) \cdot \bar{X}_{u}
$$

$\overline{\mathrm{X}}_{\mathrm{u}}$ and $\overline{\mathrm{X}}_{\mathrm{r}}$ represent the average level of teacher training frequency in the urban sample and the rural sample, respectively, $\widehat{\beta}_{\mathrm{u}}$ and $\widehat{\beta}_{\mathrm{r}}$ represent the estimated value of the coefficient when the urban sample and the rural sample are used to estimate the influence of teacher training on student performance. Therefore, the difference in the average Chinese performance of urban and rural students can be attributed to two parts: one part is due to the difference in the mean of teacher training frequency between urban and rural students, namely $\left(\overline{\mathrm{X}}_{\mathrm{u}}-\overline{\mathrm{X}}_{\mathrm{r}}\right) \bullet \widehat{\beta}_{\mathrm{r}}$, also known as the endowment effect; the other part The difference between the estimated coefficients derived from teacher training affecting the performance of urban and rural students, namely $\left(\widehat{\beta}_{\mathrm{u}}-\widehat{\beta}_{\mathrm{r}}\right) \bullet \overline{\mathrm{X}}_{\mathrm{u}}$, is also called the coefficient effect.

The endowment effect and coefficient effect of teacher training correspond to different policy improvement ideas. The significant endowment effect indicates that the urban-rural gap in teacher training opportunities is an important reason for the urbanrural gap in student performance; then follow-up policies need to increase the training opportunities for rural teachers in order to narrow the urban-rural education gap. A significant coefficient effect indicates that the urban-rural gap between teacher training quality and student resource conversion rate is an important reason for the urban-rural gap in student performance; then follow-up policies need to improve the quality of rural teacher training and the resource conversion rate of rural students to achieve educational balance. 


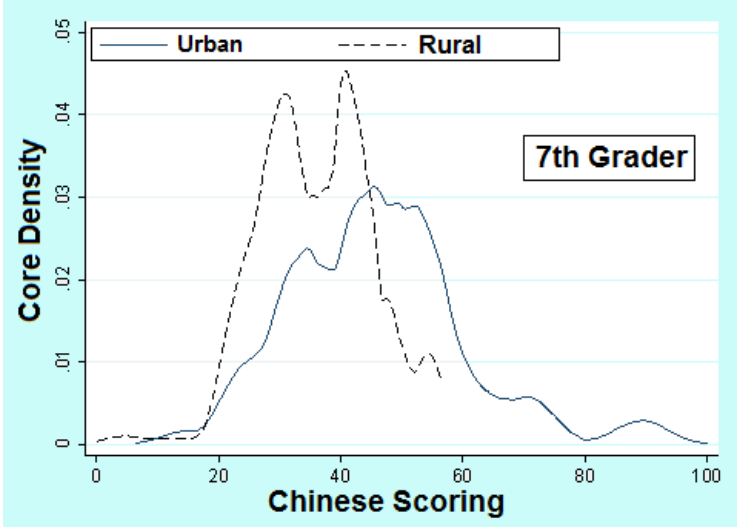

Figure 1. The Distribution of Chinese Scores of Urban and Rural Students in Seventh Graders.

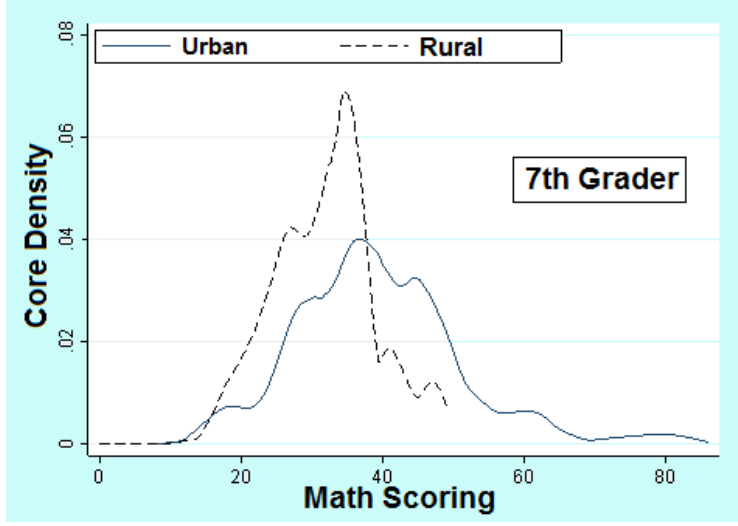

Figure 2. Distribution of Mathematics Scores of Urban and Rural Students in Seventh Graders.

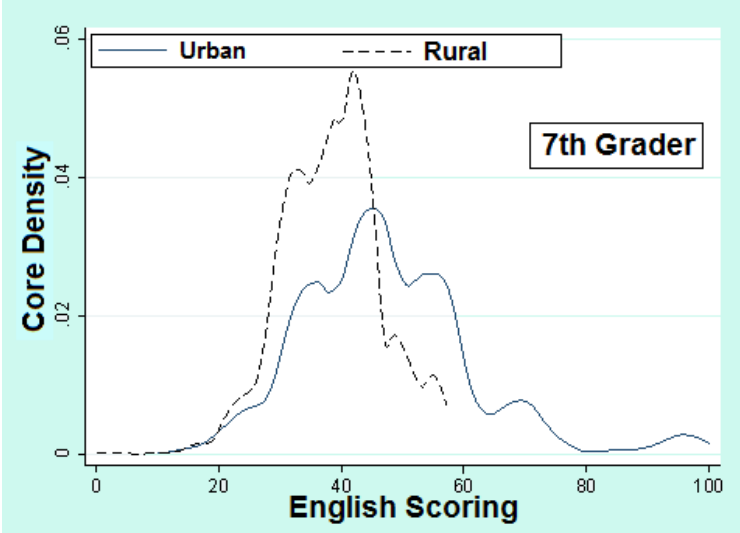

Figure 3. Distribution of English Scores of Urban and Rural Students in Seventh Graders. 


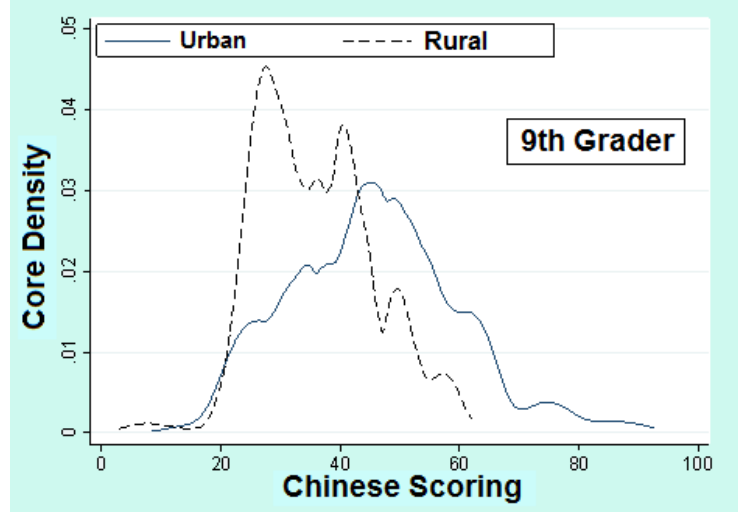

Figure 4. The Distribution of Chinese Scores of Ninth Grade Urban and Rural Students.

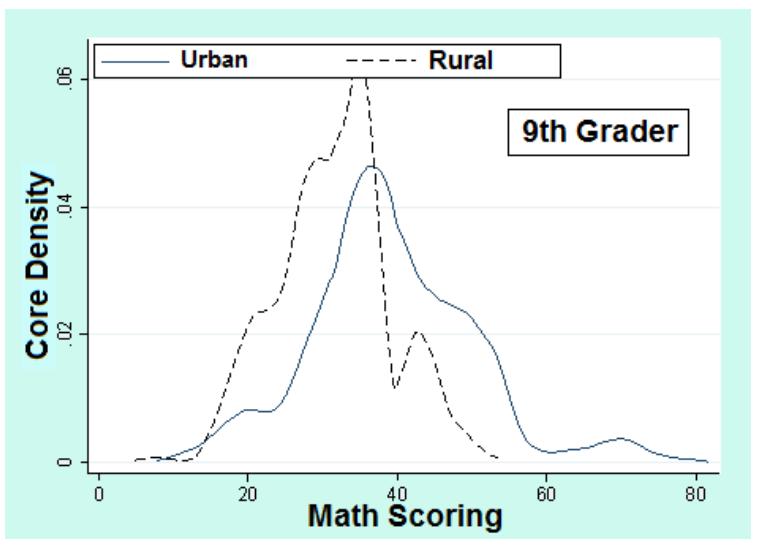

Figure 5. Distribution of Mathematics Scores of Urban and Rural Students in Ninth Graders.

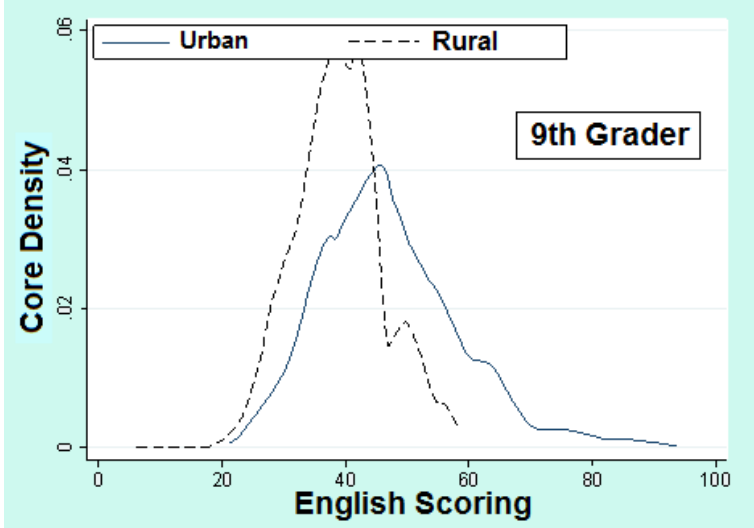

Figure 6. The Distribution of English Scores of Ninth Grade Urban and Rural Students. 


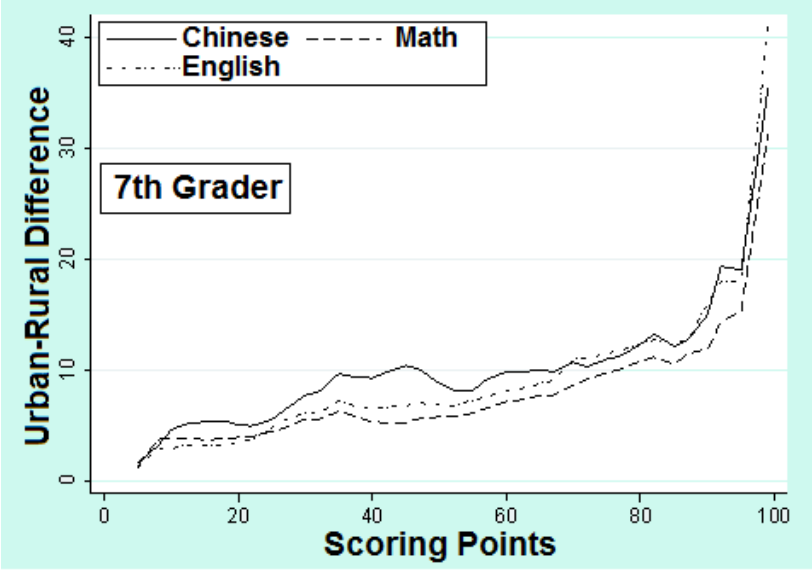

Figure 7. The Urban-Rural Gap in the Performance of Seventh Grade Students at Different Quantile.

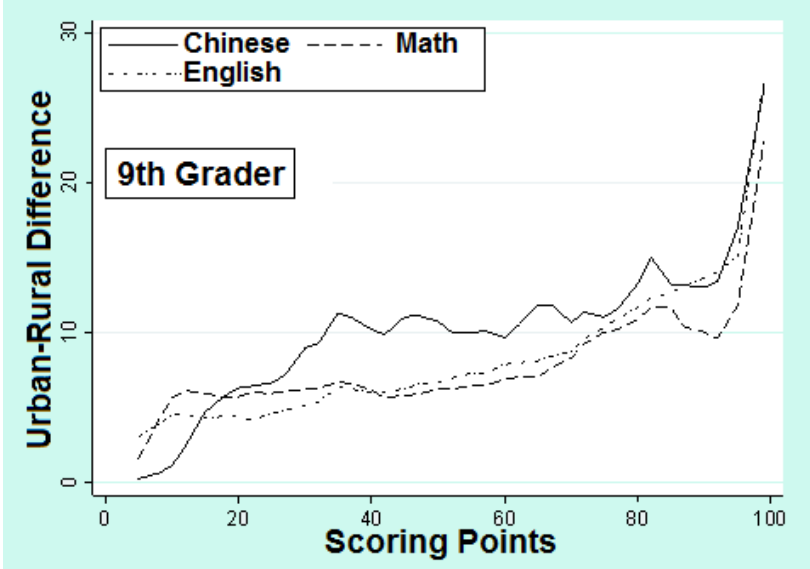

Figure 8. The Urban-Rural Gap between Grade Nine Students at Different Quantile.

\section{Results}

\section{The Status Quo of the Gap between Urban and Rural Students' Performance}

This section reveals the performance distribution of urban and rural students (Figures 1 to 6) and the performance gap between urban and rural students at different points of 
the performance distribution (Figures 7 and 8). The data shows that in the two grades, compared with urban students, the distribution of the three subjects of rural students is significantly leftward, indicating those rural students' performance in Chinese, mathematics, and English lags behind that of urban students as a whole. So, the hypothesis 1 was confirmed.

At the same time, the urban-rural gap in student performance at different quantile showed similar characteristics in both grades. As follows: First, urban students at different quantile have significantly higher scores in Chinese, mathematics, and English than the corresponding rural students. Second, the performance gap between urban and rural students presents a "ceiling effect", that is, with the increase of the quintile, the urban and rural gaps in the three subject performances of students have shown a significant expansion trend. Third, there is subject heterogeneity in the degree of the urban-rural gap in student performance; the gap between urban and rural students in different quantile in language subjects (Chinese and English) is generally greater than the gap in mathematics. These findings indicated that the performance gap between urban and rural students is more mainly reflected in the student groups with good performance and language subjects. Therefore, it is extremely important to examine the differences in the impact of teacher training on urban and rural student performance in different disciplines and different points of student performance distribution.

\section{The Influence of Teacher Training on Student Perfor- mance in Urban and Rural Areas}

This section used UQR technology to estimate the effect of teacher training on students' Chinese, mathematics, and English performance at different points of the score distribution in samples of all students, urban students, and rural students. The results are shown in Table 2.

Based on the full sample, the following results appeared robustly in different grades and different subjects: Students with different quantile of performance distribution have improved their academic performance due to teacher training, and with the increase of quantile, the effect of teacher training on student performance continued to increase. The possible reason is that, compared with students with poor performance, those with good performance generally performed better in learning habits and abilities characterized by learning initiative, participation, and interest. Moreover, the resource conversion rate of the various element inputs they face was higher (Jiang, 2017). When being taught by teacher training at the same time, students with good performance are better able to absorb and internalize the teaching improvement obtained through training into higher academic performance, and thus get more benefits from teacher training.

Next, we subdivided the sample of urban and rural students. The results showed that among urban students, teacher training benefited all students, but the degree of benefit varied with the difference in student performance. Specifically, compared with students with lower-middle grades, students with middle and above grades have achieved a greater degree of improvement in performance due to teacher training. 


\begin{tabular}{|c|c|c|c|c|c|c|c|c|c|c|}
\hline & & \multicolumn{3}{|c|}{ Full Sample } & \multicolumn{3}{|c|}{ Urban Sample } & \multicolumn{3}{|c|}{ Rural Sample } \\
\hline & & Q30 & Q50 & Q70 & Q30 & Q50 & Q70 & Q30 & Q50 & Q70 \\
\hline \multirow[t]{4}{*}{ Chinese } & $\begin{array}{l}7^{\text {th }} \\
\text { Grader }\end{array}$ & $\underset{* \star \star *}{0.042}$ & 0.111 & $\underset{* * *}{0.159}$ & $\underset{* \star *}{0.117}$ & 0.205 & $\begin{array}{l}0.147 \\
* * \star\end{array}$ & 0.012 & $\underset{* \star \star}{0.168}$ & $\begin{array}{l}0.122 \\
* * *\end{array}$ \\
\hline & & $(9.23)$ & (25.90) & (18.48) & (16.95) & (32.01) & (13.75) & $(0.80)$ & (9.54) & (8.58) \\
\hline & $\begin{array}{l}9^{\text {th }} \\
\text { Grader }\end{array}$ & $\underset{* \star \star}{0.022}$ & $\underset{* \star \star}{0.123}$ & $\underset{\star \star \star \star}{0.177}$ & $\underset{* \star *}{0.134}$ & $\underset{\star \star \star \star}{0.203}$ & $\underset{* \star \star}{0.233}$ & $\frac{-0.063}{* \star \star}$ & $\underset{\star \star \star \star}{0.119}$ & $\underset{\star \star \star \star}{0.123}$ \\
\hline & & (3.76) & (22.91) & (17.96) & (13.49) & (22.64) & (19.23) & $(-4.76)$ & (7.22) & (7.79) \\
\hline \multirow[t]{4}{*}{ Math } & $\begin{array}{l}7^{\text {th }} \\
\text { Grader }\end{array}$ & $\underset{* \star \star}{0.044}$ & $\underset{* \star \star}{0.075}$ & $\underset{* \star \star}{0.133}$ & $\underset{* \star *}{0.082}$ & $\underset{\star \star \star \star}{0.155}$ & $\underset{* \star \star}{0.137}$ & -0.012 & $\underset{* \star \star}{0.068}$ & $\underset{* \star *}{0.056}$ \\
\hline & & (11.35) & (25.99) & (18.10) & (16.85) & (28.53) & (14.32) & $(-0.82)$ & (6.37) & (6.39) \\
\hline & $\begin{array}{l}9^{\text {th }} \\
\text { Grader }\end{array}$ & $\underbrace{0.032}_{* \star *}$ & 0.068 & $\int_{* \star *}^{0.131}$ & 0.080 & 0.143 & 0.192 & -0.045 & 0.057 & $\underset{* \star \star *}{0.056}$ \\
\hline & & (7.27) & (22.67) & (16.16) & (15.37) & (20.59) & (15.23) & $(-3.41)$ & (5.25) & (6.43) \\
\hline \multirow[t]{4}{*}{ English } & $\begin{array}{l}7^{\text {th }} \\
\text { Grader }\end{array}$ & 0.049 & 0.090 & 0.143 & 0.094 & $\underset{* \star \star}{0.157}$ & 0.167 & -0.046 & 0.087 & 0.075 \\
\hline & & (11.17) & (26.02) & (18.39) & (16.06) & (24.93) & (14.68) & $(-3.06)$ & (7.36) & (6.69) \\
\hline & $\begin{array}{l}9^{\text {th }} \\
\text { Grader }\end{array}$ & $\underset{* \star \star}{0.023}$ & $\underset{* \star \star}{0.080}$ & $\underset{* \star \star}{0.145}$ & $\underset{* \star \star \star}{0.087}$ & $\underset{\star \star \star \star}{0.165}$ & $\underset{* \star \star}{0.167}$ & -0.031 & $\underset{\star \star \star \star}{0.046}$ & $\underset{* * *}{0.060}$ \\
\hline & & (5.75) & (22.72) & (18.75) & $(13.90)$ & $(23.51)$ & $(12.58)$ & $(-2.41)$ & (4.99) & $(6.29)$ \\
\hline
\end{tabular}

Note: ${ }^{*} p<0.1,{ }^{* *} p<0.05,{ }^{* * *} p<0.01$. The $T$ value is in parentheses. Each coefficient in the table comes from an independent model. Due to space limitations, the estimated results of the control variables are not presented in the table.

The above results robustly exist in different grades and different subjects, and are similar to the estimated results based on the sample of all students.

In the sample of rural students, teacher training can only benefit students with intermediate and above grades. Students with intermediate and lower grades cannot be improved by teacher training. What's more, students with poor grades in the ninth grade will have a significant decline in all three subjects due to teacher training. This is because rural students with low-to-middle grades are the worst-developed group in China's entire education system. They generally lack learning initiative, and the learning process is more dependent on the teacher's constant supervision (Qing, 2009). However, training may bring conflicts between working and teaching to teachers, reduce the time allocation for teaching and class preparation, and the attention and urge to students. In the end, the academic performance of students with low grades is difficult to benefit from teacher training. For urban students at the lower-middle level, their academic performance, learning ability and habits are generally better than those of the correspondingly ranked students in rural areas; in addition, the parents of urban students are more likely to have higher education levels and educational participation levels; and therefore, the children can be guided after class, and ultimately they have not been negatively affected by teacher training. Therefore, the negative relationship between teacher training and student performance is mainly reflected in the rural student groups with poor per- 
formance. In fact, Jacob and Lefgren (2004) based on data from USA schools that are highly impoverished and whose student performance was extremely low, found that teacher training could not improve student performance, and the results would not change due to differences in students' previous academic foundation. This finding better supports the reliability of the conclusions of this study for rural student groups with poor performance.

Further, horizontally compare the urban-rural gap in the effect of teacher training on the improvement of student performance. The results found that in different grades and different disciplines, the effect of improving the performance of rural students due to teacher training was significantly smaller than that of urban students; this phenomenon steadily exists at different quantile of the distribution of student performance. There are two possible explanations for this. (i) The training opportunities and quality of rural teachers are not as good as that of urban teachers. (ii) Compared with urban students, rural students have a poorer academic foundation and ability; therefore, the resource conversion rate is lower. These all may limit the effectiveness of teacher training in rural areas.

In sum, teacher training could help improve the academic performance of urban students with different performance levels and rural students with middle and above performance levels. However, it could not bring a positive impact on rural students with lower-middle performance levels. In addition, the performance improvement effect of urban teacher training was higher than the corresponding effect of rural teachers. So far, Hypothesis 2 has been confirmed. Therefore, it can be speculated that the urban-rural gap in teacher training will cause the gap in academic performance of urban and rural students.

\section{The Influence of Teacher Training on the Achievement Gap between Urban and Rural Students}

This section used both UQR and OB decomposition techniques. Decomposes the performance gap between urban and rural students, and mainly presents the explanation strength of the urban-rural gap in teacher training. The results are shown in Table 3.

The decomposition results of the seventh grade showed that in different subjects and different quantile, teacher training could explain the urban-rural gap in student performance to a certain extent. As the quantile increases, the explanatory power of the endowment effect of teacher training showed a trend of first increasing and then decreasing, but the fluctuation range was relatively slow and always maintained above $10 \%$. At the same time, the explanatory power of the coefficient effect of teacher training decreased rapidly from more than $20 \%$ of the low quantile to less than $10 \%$ of the high quantile.

Furthermore, comparing the relative importance of the two effects of teacher training at different quantile of performance distribution, it is found that: (i) For urban and rural students whose performance is below average, the performance gap could easily be explained by the coefficient effect of teacher training; (ii) For urban and rural 
Table 3. Decomposition Results of Teacher Training on the Urban-Rural Gap in Student Performance.

\begin{tabular}{|c|c|c|c|c|c|c|c|c|}
\hline & & & \multicolumn{3}{|c|}{ Seventh Grade } & \multicolumn{3}{|c|}{ Ninth Grade } \\
\hline & & & Q30 & Q50 & Q70 & Q30 & Q50 & Q70 \\
\hline \multirow[t]{4}{*}{ Chinese } & $\begin{array}{l}\text { Endowment } \\
\text { effect }\end{array}$ & $\begin{array}{l}\text { Estimated } \\
\text { Value } \\
\end{array}$ & $0.935^{\star \star *}$ & $1.629^{* * *}$ & $1.101^{\star * *}$ & $0.636^{\star * *}$ & $0.958^{* * *}$ & $1.060^{\star * *}$ \\
\hline & & Percentage & $12.05 \%$ & $18.49 \%$ & $10.25 \%$ & $7.08 \%$ & $8.91 \%$ & $9.90 \%$ \\
\hline & $\begin{array}{l}\text { Coefficient } \\
\text { effect }\end{array}$ & $\begin{array}{l}\text { Estimated } \\
\text { Value }\end{array}$ & $1.724^{* \star *}$ & $0.948^{* * *}$ & 0.380 & $3.098^{* * *}$ & $1.497^{* * *}$ & $1.760^{\star * *}$ \\
\hline & & Percentage & $22.21 \%$ & $10.76 \%$ & $3.54 \%$ & $34.48 \%$ & $13.92 \%$ & $16.44 \%$ \\
\hline \multirow[t]{4}{*}{ Math } & $\begin{array}{l}\text { Endowment } \\
\text { effect }\end{array}$ & $\begin{array}{l}\text { Estimated } \\
\text { Value }\end{array}$ & $0.641^{* * *}$ & $1.147^{* * *}$ & $1.041^{\star * *}$ & $0.387^{* * *}$ & $0.647^{\star * *}$ & $0.893^{* * *}$ \\
\hline & & Percentage & $11.42 \%$ & $19.75 \%$ & $12.00 \%$ & $6.18 \%$ & $10.35 \%$ & $10.71 \%$ \\
\hline & $\begin{array}{l}\text { Coefficient } \\
\text { effect }\end{array}$ & $\begin{array}{l}\text { Estimated } \\
\text { Value }\end{array}$ & $1.531^{\star \star \star}$ & $1.336^{\star \star \star}$ & $0.877^{\star \star \star}$ & $1.963^{* * *}$ & $1.363^{\star \star \star}$ & $1.949^{* * *}$ \\
\hline & & Percentage & $27.28 \%$ & $23.00 \%$ & $10.11 \%$ & $31.33 \%$ & $21.81 \%$ & $23.38 \%$ \\
\hline \multirow[t]{4}{*}{ English } & $\begin{array}{l}\text { Endowment } \\
\text { effect }\end{array}$ & $\begin{array}{l}\text { Estimated } \\
\text { Value } \\
\end{array}$ & $0.742^{\star \star \star}$ & $1.201^{* * *}$ & $1.252^{\star \star \star}$ & $0.425^{\star \star *}$ & $0.758^{* * *}$ & $0.778^{* * *}$ \\
\hline & & Percentage & $12.02 \%$ & $17.49 \%$ & $11.36 \%$ & $8.28 \%$ & $11.30 \%$ & $8.86 \%$ \\
\hline & $\begin{array}{l}\text { Coefficient } \\
\text { effect }\end{array}$ & $\begin{array}{l}\text { Estimated } \\
\text { Value }\end{array}$ & $2.239^{\star * *}$ & $1.104^{\star \star *}$ & $1.014^{\star * *}$ & $1.945^{\star \star *}$ & $1.873^{\star \star *}$ & $1.422^{\star * *}$ \\
\hline & & Percentage & $36.28 \%$ & $16.08 \%$ & $9.20 \%$ & $37.88 \%$ & $27.92 \%$ & $16.20 \%$ \\
\hline
\end{tabular}

Notes: (1) the above decomposition process also control the variables at the school level, the family level variables and school level variables, space is limited, the results are not eleven out . (2) The endowment effect percentage in the table refers to the ratio of the explanatory strength of the endowment effect of teacher training to the explanatory strength of the endowment effect of all variables included in the model, and the coefficient effect percentage refers to the explanatory strength of the coefficient effect of teacher training and the model includes The ratio of explanatory strengths of the coefficient effects of all variables.

students with intermediate and above grades, their performance gap was suitable to be explained by the endowment effect of teacher training. Similarly, the decomposition results of the ninth grade showed that both endowment and coefficient effect of teacher training in different subjects and different quantile could explain the urban-rural gap in student performance to a certain extent. But relatively, the explanatory strength of the coefficient effect always dominated at different quantile. Therefore, Hypothesis 3 is confirmed.

In addition, comparing the results of the seventh and ninth grades, we found that the greater urban-rural gap in the performance of ninth grade students was explained by the coefficient effect of teacher training, and the explanatory effect of the endowment effect of teacher training was relatively small. If the coefficient effect of teacher training was understood as the difference in the efficiency of urban and rural students' conversion of the positive effects of teacher training into their own performance improvement, it meant that the resource conversion rate of rural students was lower than that of urban students. The possible explanation is that capacity formation is cumulative. As the grade increases, the differences in the accumulation of learning foundation in the early stage are gradually showed up, and will affect the subsequent academic development. 
The above results indicated that the training frequency of rural teachers was significantly lower than that of urban teachers; the efficiency of transforming rural teacher training into student performance was not as efficient as the corresponding situation in the city; these were the potential reasons why rural students' academic performance significantly lags behind urban students. In fact, the training frequency of urban teachers in grade seven (22.973 times) was significantly higher than that of rural teachers (15.545 times). The training frequency of urban teachers in grade 9 (20.501 times) was significantly higher than that of rural teachers (15.844 times). Moreover, the conversion rate of teacher training was comprehensively affected by the quality of training and the ability of students. Therefore, in order to reduce the performance gap between urban and rural students, it is necessary to increase the training opportunities for rural teachers, improve the quality of rural teacher training, and improve the early learning ability of rural students. In order to achieve a balanced development of urban and rural education and ensure the quality of teachers' inputs, the family's inputs, which are closely related to the formation of students' abilities, cannot be ignored.

\section{Conclusion and Suggestion}

Based on CEPS data, this study examined the relationship between teacher training and student performance and its impact on the urban-rural gap in student performance. We found that: First, in the entire academic performance distribution, rural students lagged behind that of urban students, and this gap was more obvious at high quantile and in language subjects. Second, teacher training helped improve the performance of students with different academic levels in cities and rural students with middle and above levels, but it could not improve the performance of rural students with middle and below levels. In addition, the overall effect of teacher training on urban students was significantly higher than that of rural students. Third, the urban-rural gap in teacher training explained the urban-rural gap in student performance distribution to a certain extent. The endowment effect and coefficient effect of teacher training were both important reasons for the urban-rural gap in student performance, but the relative size of the two varied with grades and academic performance. Therefore, the findings of this study have enlightenment to formulate education policies that narrow the development gap between urban and rural students.

First, innovate and improve rural teacher training policies and systems, and provide rural teachers with more high-quality training activities. This study found that only when rural teachers obtain the "dual guarantee" of training opportunities and quality, can they contribute to the balanced development of urban and rural education. However, in reality, many rural schools had not fully implemented the teacher training funding guarantee policy, which limited the frequency of rural teacher training (Chen \& Wang, 2013). Some rural teachers reported that the training content was too theoretical, the teaching format was superficial, and the guiding role was very limited (Pang, et al., 2020). Therefore, it is necessary to fully implement the provisions on the proportion of rural school teacher training funds to public funds; increase financial support for rural teacher training projects; and provide rural teachers with more training opportunities. 
Meanwhile, training activities should effectively address the characteristics of rural schools and teachers, and increase the training of local knowledge and the psychological problems of rural left-behind children and their ability to improve the applicability of training.

Second, effectively strengthen parental participation and popularize rural preschool education to help rural students lay a solid academic foundation and increase their resource conversion rate. We found that the coefficient effect of teacher training could significantly explain the performance gap between urban and rural students at different quantile of the distribution of student performance in different grades. To a certain extent, it reflected that the resource conversion rate of rural students was significantly behind that of urban students, which was an essential reason why they have been behind urban students for a long time. The disadvantage of rural students in the resource conversion rate is caused by the students' poor academic foundation, lack of family resources and low level of parental participation. Therefore, in the short term, school administrators should encourage "family and pre-school education together", especially emphasizing, accepting and guiding the participation of parents of students with poor academic performance. In the long run, education reform needs to pay attention to the importance of early education for rural students. Popularize rural preschool education, extend the period of rural preschool education, improve the quality of care and education, and ensure that rural students have a solid knowledge reserve to improve the efficiency of their resource input conversion.

Finally, for student groups with different characteristics, differentiated teacher training intervention programs need to be adopted to more effectively narrow the urbanrural education gap. This study found that for students with middle and above levels in the lower grades, the part of the performance gap explained by the teacher training endowment effect was greater than the explanatory power of the coefficient effect. The opposite was true for senior students and students whose grades are below average. Therefore, for the former type of rural students, teachers can directly provide more high-quality training opportunities, and at the same time, gradually increase the student's resource conversion rate. For the latter type of rural students, before increasing the frequency of high-quality teacher training, it is more necessary to focus on improving the student's resource conversion rate. The above-mentioned differentiated teacher training intervention programs can bring more obvious effects to improving the education gap between urban and rural areas. In addition, senior rural students with poor performance may be negatively affected by teacher training, which reduces teaching time or loses teacher supervision. And they are at the critical stage of the entrance examination, so they can make full use of the network platform and innovate training models under the current background of "Internet + education" to improve the time efficiency of these teachers' participation in training.

\section{Note:}

1. In 1996, according to the standard that the proportion of students meeting the national reading standard in schools was less than 15\%, CPS selected 71 elementary schools out of 489 elementary schools for intervention. Its main purpose is to provide these schools with professional funds 
for teacher training and enhancement of teacher professional development.

\section{References}

Angrist, J.D., \& Lavy, V. (2001). Does teacher training affect pupil learning? Evidence from matched comparisons in Jerusalem public schools. Journal of Labor Economics, 19(2):343-369. DOI:

https://doi.org/10.1086/319564

Blinder, A.S. (1973). Wage discrimination: reduced form and structural estimates. Journal of Human Resources, 8(4):436-455. DOI: https://doi.org/10.2307/144855

Chen, B.L. (2008). Path dependence in education acquisition. Peking University Education Review, 2008(4): 93-106. DOI: https://doi.org/10.3969/j.issn.16719468.2008.04.009

Chen, X.M.. \& Wang Z.M. (2013). A survey of teacher training in compulsory education: status quo, problems and suggestions. Open Education Research, 19 (4):11-19. DOI: https://doi.org/CNKI:SUN:JFJJ.0.2013-04$\underline{004}$

Firpo, S., Fortin, N.M.. \& Lemieux, T. (2009) Unconditional quantile regressions. Econometrics, 77(3):953-973. DOI:

https://doi.org/10.3982/ECTA6822

Jacob, B.A.. \& Lefgren, L. (2004). The impact of teacher training on student achievement: quasi-experimental evidence from school reform efforts in Chicago. The Journal of $\mathrm{Hu}$ man Resources, 39(1):50-79. DOI:

https://doi.org/10.2307/3559005.

Jiang, Q.C. (2017). Family background, school quality and differences in cognitive skills between urban and rural adolescents. Education and Economy, 2017(6):21-30. DOI: https://doi.org/10.3969/j.issn.10034870.2017.06.003

Liu, J., Ma, Y.R.. \& Kang, H.H. (2020). A metaanalysis study on the effect of teacher coaching post-service training. Educational Development Research, 40(8):71-77. DOI: https://doi.org/10.3969/j.issn.1008$\underline{3855.2020 .08 .013}$
Lounkaew, K. (2013). Explaining urban-rural differences in educational achievement in Thailand: evidence from PISA literacy data. Economics of Education Review, 37(6):213225. DOI:

https://doi.org/10.1016/j.econedurev.2013.09 .003

Loyalka, P., Popova, A., Li, G.. \& Shi, Z.L. (2019). Does teacher training actually work? Evidence from a large-scale randomized evaluation of a national teacher training program. American Economic Journal: Applied Economics, 11 ( 3):128-154. DOI: https://doi.org/10.1257/app.20170226

Ministry of Education of China. (2019, March 26). Introduction of the supervision and evaluation of the balanced development of compulsory education nationwide in 2018 [EB/OL]. [2021-03-13]. Retrieved from http://www.moe.gov.cn/fbh/live/2019/50415 /twwd/201903/t20190 326_375413.html

Oaxaca, R.L. (1973). Male- female wage differentials in urban labor markets. International Economic Review, 14(3):693-709. DOI: https://doi.org/10.2307/2525981

Pang, L.J., Jin, Z.F., Yang, X.M. \& Wang, H.L. (2020). Improving the construction of the teaching staff to help rural revitalization strategies-institutional thinking and policy recommendations. Journal of Beijing Normal University (Social Science Edition), 2020(6):5-14. DOI:

http://wkxb.bnu.edu.cn/CN/Y2020/V0/I6/5

Peng, B. (2014). Research on the academic gap between urban and rural students in compulsory education: Based on the perspective of educational equity. Journal of Educational Science of Hunan Normal University, 13(5):73-79.

Qi. X., \& Zheng, L. (2019). An empirical study on the urban-rural academic gap and its influencing factors. Chinese Journal of Education, 2019(3):36-39. 
Sun \& Du. Teacher Training in Educational Gap between Urban and Rural Students.

Qing, S.L. (2009). Analysis of the status quo of learning styles of primary and middle school students. Educational Science Research, 2009(10):52-55. DOI: https://doi.org/CNKI:SUN:JYKY.0.2009$\underline{10-017}$

Ross, J., \& Bruce, C. (2007). Professional development effects on teacher efficacy: results of randomized field trial. The Journal of Educational Research, 101(1):50-60. DOI: https://doi.org/10.3200/JOER.101.1.50-60

Wang, L., Li, M.J., Abbey, C., \& Scott, R. (2018). Human capital and the middle trap: how many of China's youth are going to high school? The Developing Economics, 56(2):82-103. DOI: https://doi.org/10.1111/deve.12165

Wu, Z.H., \& Qin, Y.Y. (2020). China Rural Education Development Report 2019[M]. Beijing: Beijing Normal University Press: 279.

Zhang, L. (2019). Research on the urban-rural difference in academic achievement: An empirical analysis based on the Growth Tracking Survey of Capital University. Fudan Education Forum, 17(1): 61-67. DOI: https://doi.org/10.13397/j.cnki.fef.2019.01.0 11

Zhang, L.X., Lai, F., \& Pang, X.P. (2013). The impact of teacher training on teacher and student outcomes: evidence from a randomized experiment in Beijing migrant schools. Journal of Development Effectiveness, 5(3):339-358.

Zhao, X., \& Xie, X.R. (2019). The progress and trend of rural teacher training research in the 40 years of reform and opening up. Educa- tional Research and Experiment,

2019(1):61-67. DOI:

https://doi.org/CNKI:SUN:YJSY.0.2019-01$\underline{009}$

Zheng, X.T., Sun, Z.Y., \& Lu, X.H. (2019). Why does the theory of "reading uselessness" return to the countryside? An explanation of the change in the rate of return to education for individuals of different backgrounds. $\mathrm{La}$ bor Economic Research, 7(5):53-77. DOI: https://doi.org/CNKI:SUN:LDJJ.0.2019-05$\underline{003}$

Zhou, Y., \& Yang, T.C. (2019). Rural teacher training and student performance from the perspective of targeted poverty alleviation through education. Educational Research and Experiment, 2019(2): 53-58. DOI: https://doi.org/CNKI:SUN:YJSY.0.2019-02$\underline{009}$

Zhu, D.Q., Li, P., \& Song, N.Q. (2017) Report on the Balanced Development of Compulsory Education in China: Based on Evidence from the Third-Party Evaluation of the "Education Planning Outline". Journal of East China Normal University (Education Science Edition), 35(1):63-77. DOI: http://dx.doi.org/10.16382/j.cnki.10005560.2017.01.007

Zong, X.H., Yang, S.H., \& Qin, Y.Y. (2018). Pursuing fair and quality education: Influencing factors and balancing strategies of the quality gap of urban and rural compulsory education in the new era. Educational Research of Tsinghua University, 39(6):47-57. DOI: https://doi.org/10.14138/j.10014519.2018.06.004711

Received: 11 October 2021

Revised: 30 October 2021

Accepted: 05 November 2021

The Chinese version of this article has been published in Education Economy, 2021, 37(2):47-57. The English version has been authorized for being publication in BECE by the author(s) and the Chinese journal.

孙冉, 杜屏. (2021). 教师培训能缩小城乡学生的学业差距吗?一一来自 CEPS 基线数据的经验证 据. 教育与经济, 37(2):47-57. 